BUNDA EDU-MIDWIFERY JOURNAL (BEMJ)

p-ISSN: 26227482 dan e-ISSN: 26227487

Vol. 4 No. 2 (2021)

\title{
HUBUNGAN USIA MENARCHE, MAKANAN CEPAT SAJI (FAST FOOD), STRESS DAN OLAHRAGA DENGAN KEJADIAN DISMENOREA PADA REMAJA PUTRI DI MAN 2 LEBAK BANTEN
}

\author{
Desy Qomarasari \\ Politeknik Tiara Bunda \\ E-Mail: desy.qomarasari@gmail.com
}

\author{
Keywords : \\ menarche, fast \\ food, stress, \\ exercise, \\ dysmenorrhea
}

\begin{abstract}
Dysmenorrhea is pain or tenderness in the lower abdomen that occurs during a woman's menstrual cycle. Dysmenorrhea is caused by an increase in the hormone prostaglandin. Factors that influence the occurrence of dysmenorrhea are early menarche (age of first menstruation < 12 years), lack of or never exercise, stress, prolonged menstrual cycle or menstrual duration more than normal (7 days), alcohol consumption, and smoking.

The purpose of this study was to determine the relationship between age at menarche, fast food (fast food), stress and exercise with the incidence of dysmenorrhea.

This research method is an analytic observational research with a cross sectional research design. The research location is at MAN 2 Lebak. The population in this study were teenage girls in grades $X$, XI and XII, totaling 163 people. While the sampling technique using the Proportional Random Sampling technique by lottery. The number of samples is 105 respondents. Data analysis with univariate and bivariate using chi square statistical test.

The results of this study were dysmenorrhoea respondents with congestive pain (61.9\%), menarche age $<12$ years $(84.8 \%)$, consuming fast food that was not good (65.7\%), stress (63.8\%) and rarely doing sports $(81.0 \%)$. There is a relationship between the age of menarche (0.022), fast food (0.029), stress (0.006) and exercise (0.015) with the incidence of dysmenorrhea.

The conclusion of this study is that there is a relationship between age at menarche, fast food, stress and exercise with the incidence of dysmenorrhea.
\end{abstract}

\footnotetext{
ABSTRAK

Dismenorea adalah rasa sakit atau nyeri pada bagian bawah perut yang terjadi saat wanita mengalami siklus menstruasi. Dismenorea disebabkan oleh hormon prostaglandin yang meningkat. Faktorfaktor yang mempengaruhi terjadinya dismenorea yaitu menarche dini (usia pertama kali menstruasi < 12 tahun), kurang atau tidak pernah berolah raga, stress, siklus haid memanjang atau lama haid lebih dari normal (7 hari), mengkonsumsi alkohol, dan merokok.
} 
Tujuan penelitian ini adalah untuk mengetahui hubungan usia menarche, makanan cepat saji (fast food), stress dan olahraga dengan kejadian dismenorea.

Metode penelitian ini merupakan jenis penelitian observasional analitik dengan desain penelitian yang digunakan adalah cross sectional. Lokasi penelitian di MAN 2 Lebak. Populasi dalam penelitian ini yaitu remaja putri kelas X, XI dan XII yang berjumlah 163 orang. Sedangkan teknik pengambilan sampel dengan menggunakan teknik Proportional Random Sampling dengan cara undian. Jumlah sampel 105 responden. Analisis data dengan univariat dan bivariat dengan menggunakan uji statistik chi square.

Hasil penelitian ini responden dismenorea dengan nyeri kongestif (61,9\%), usia menarche <12 tahun (84,8\%), mengkonsumsi makanan cepat saji (fast food) yang kurang baik (65,7\%), stress $(63,8 \%)$ dan jarang melakukan olahraga (81,0\%). Ada hubungan usia menarche (0,022), makanan cepat saji (fast food) (0,029), stress $(0,006)$ dan olahraga $(0,015)$ dengan kejadian dismenorea.

Kesimpulan dari penelitian ini ada hubungan antara usia menarche, makanan cepat saji (fast food), stress dan olahraga dengan kejadian dismenorea.

\section{PENDAHULUAN}

Masa remaja merupakan masa peralihan dari masa pubertas ke dewasa, yaitu pada umur 11-20 tahun. Pada masa peralihan tersebut individu matang secara fisiologik, psikologik, mental emosional dan sosial. Masa remaja ditandai dengan munculnya karakteristik seks primer, yang dipengaruhi oleh mulai bekerjanya kelenjar reproduksi. Pubertas ditandai dengan munculnya pertumbuhan badan yang cepat, timbulnya ciri-ciri kelamin sekunder, menarche dan perubahan psikis. Pada wanita, pubertas ditandai dengan terjadinya haid atau menstruasi. Haid merupakan proses keluarnya darah dari rahim melalui vagina setiap bulan selama masa usia subur (Wardani, 2021).

Menstruasi yang pertama kali dialami oleh seorang wanita biasanya terdapat gangguan kram, nyeri dan ketidaknyamanan yang dihubungkan dengan mentruasi disebut dismenorea. Kebanyakan wanita mengalami tingkat kram yang bervariasi, pada beberapa wanita hal ini muncul dalam bentuk rasa tidak nyaman, sedangkan beberapa yang lain menderita rasa sakit yang mampu menghentikan aktivitas sehari-hari dan terganggunya siklus menstruasi (Wardani, 2021).

Menurut data dari WHO (Dalam Gumangsari, 2014), didapatkan kejadian $90 \%$ wanita yang mengalami dismenorea berat. Prevalensi dismenore di Indonesia sebesar $64,25 \%$ yang terdiri dari $54,89 \%$ dismenore primer dan 9,36\% dismenore sekunder. Dismenore primer pada umumnya terjadi setelah 1-3 tahun dari menarche.

Dari penelitian Agustini (2019) dengan 80 responden terdapat 37 siswi menarche dini dan sebanyak 33 siswi $(89,2 \%)$ mengalami dismenore, sebanyak 4 siswi (10,8\%) tidak mengalami dismenore. Penelitian lain dari Indahwati (2017) terhadap 63 responden terdapat 35 responden $(55.6 \%)$ sering menggonsumsi fast food dengan kejadian dismenore 27 responden $(42.9 \%)$ dan 8 responden $(12.7 \%)$ tidak dismenore, sedangkan 28 responden (44.4\%) jarang menggonsumsi fast food didapatkan 14 
responden $(22.2 \%)$ dismenore dan 14 responden $(22.2 \%)$ tidak dismenore.

Selain itu ada penelitian Nuraini (2021), dari 87 sampel yang dapat diteliti paling banyak responden mengalami tingkat stres sedang sebanyak 31 responden $(35,6 \%)$. Hasil uji statistika menunjukkan bahwa terdapat hubungan antara stres dengan dismenorea primer pada mahasiswi Fakultas Kedokteran dengan nilai $\mathrm{p}=$ 0,033 . Dan juga ada penelitian Temesvari (2019), dengan jumlah responden 168 siswi didapatkan hasil 97 siswi (58\%) menyatakan kurang melakukan kebiasaan olahraga dan sebanyak 56 siswi (66.7\%) mengalami dismenor primer. Hasil uji bivariat terdapat hubungan kebiasaan olahraga dengan dismenor primer ( $\mathrm{p}$-value 0.014).

Dismenore merupakan rasa nyeri yang terjadi saat mentruasi, dimana hal ini disebabkan karena adanya kontraksi otot uterus sewaktu pengeluaran darah mentruasi yang dapat berlangsung antara 32-48 jam. Kejadian ini dianggap normal dalam proses menstruasi, dengan derajat nyeri yang berbeda-beda. Pada remaja, kejadian dismenore lebih banyak merupakan dismenore primer (nyeri mentruasi normal) dimana kejadian ini dapat berkurang intensitas nyerinya disaat seorang perempuan telah melahirkan/ sejalan bertambahnya usia. Akan tetapi, pada beberapa kasus dismenore (dismenore sekunder) diakibatkan karena faktor penyakit yang berkaitan dengan organ reproduksi (Pintam, 2018).

Dismenorea disebabkan oleh hormon prostaglandin yang meningkat, peningkatan hormon prostaglandin disebabkan oleh menurunnya hormon-hormon estrogen dan progesteron menyebabkan endometrium yang membengkak dan mati karena tidak dibuahi. Peningkatan hormon prostaglandin menyebabkan otot-otot kandungan berkontraksi dan menghasilkan rasa nyeri (Sukarni dan Wahyu, 2013).
Faktor-faktor yang mempengaruhi terjadinya dismenorea primer yaitu menarche dini (usia pertama kali menstruasi < 12 tahun), kurang atau tidak pernah berolah raga, siklus haid memanjang atau lama haid lebih dari normal (7 hari), mengkonsumsi alkohol, riwayat keluarga yang positif, dan merokok (Harsinta, 2014). Sedangkan menurut Pintam (2018) Gangguan haid disebabkan berbagai faktor seperti berat badan, aktivitas fisik, stres, diet, paparan lingkungan, sinkronisasi proses menstrual, gangguan endokrin, gangguan perdarahan dan siklus menstruasi.

Dari hasil studi pendahuluan yang dilakukan di sekolah MAN 2 Lebak terdapat 239 siswi dan seluruhnya sudah menstruasi. Berdasarkan hasil wawancara pada 20 orang siswi yang mengalami dismenorea sebanyak 9 orang siswi (45\%) akibat faktor stress dari padatnya pembelajaran untuk menghadapi ujian akhir sekolah, 5 orang (25\%) mengalami dismenorea karena kurangnya aktivitas fisik atau olahraga (kejadian dismenorea akan meningkat pada wanita yang kurang melakukan olahraga sehingga oksigen tidak tersalurkan ke pembuluh darah). 5 orang (25\%) mengalami dismenorea dikarenakan seringnya mengkonsumsi makanan cepat saji (fast food) para siswi yang suka mengkonsumsi fash food dan memiliki berat badan yang merupakan faktor resiko terjadinya dismenorea 1 orang (5\%) yang mengalami penyebab-penyebab lainya.

Dengan masih tingginya angka kejadian dismenorea dan banyaknya hasil penelitian sebelumnya yang berbeda dengan teori yang ada, membuat peneliti tertarik untuk melakukan penelitian dengan rumusan masalah yaitu apakah terdapat hubungan usia menarche, makanan cepat saji (fast food), stress dan olahraga terhadap kejadian dismenorea.

Penelitian ini bertujuan untuk membuktikan teori yang sudah ada mengenai hubungan usia menarche, makanan cepat saji (fast 
food), stress dan olahraga dengan kejadian dismenorea.

\section{METODE}

Dalam penelitian ini menggunakan penelitian observasional analitik dengan desain penelitian yang digunakan adalah cross sectional. Populasi dalam penelitian ini yaitu remaja putri kelas X, XI dan XII MAN 2 LEBAK yang berjumlah 163 orang. Sedangkan teknik pengambilan sampel dengan menggunakan teknik teknik Proportional Random Sampling dengan cara undian. Untuk menentukan ukuran sampel pada populasi, penelitian ini menggunakan tabel Isaac dan michael, yang dikutip dari Sugiyono (2018) yaitu didapatkan sampel 105 orang.

Variabel bebas dalam penelitian ini adalah usia menarche, makanan cepat saji (fast food), stress dan olahraga. Sedangkan untuk variabel terikatnya adalah dismenorea. Alat pengumpulan data dalam penelitian ini adalah kuesioner. Teknik pengolahan data dengan cara Editing (pemeriksaan), Coding (pengkodean), Processing (pemasukan data), Tabulating (tabulasi). Analisa data menggunakan univariat dan bivariat dengan menggunakan batas kemaknaan sebesar 5\% $(\alpha=0,05)$ dengan uji chi square. Penyajian data dalam bentuk tabel frekuensi dan persentase.

\section{HASIL DAN PEMBAHASAN}

Analisis data yang digunakan dengan univariat dan bivariat digunakan untuk mengetahui frekuensi dan hubungan antara usia menarche, makanan cepat saji (fast food), stress dan olahraga terhadap kejadian dismenorea dengan uji chi-square.

\section{A. Analisis Univariat}

Tabel 1. Karakteristik Usia Menarche, Fast food, Stress, Olahraga dan Kejadian Dismenorea

\begin{tabular}{|c|c|c|c|}
\hline No & Variabel & $\mathbf{N}$ & $(\%)$ \\
\hline \multirow[t]{4}{*}{1.} & Dismenorea & & \\
\hline & - Nyeri kongestif & 65 & 61,9 \\
\hline & - $\quad$ Nyeri spasmodic & 40 & 38,1 \\
\hline & Total & 105 & 100 \\
\hline \multirow[t]{4}{*}{2} & Usia Menarche & & \\
\hline & - $\quad$ 12-14 tahun & 16 & 15,2 \\
\hline & $-\quad<12$ tahun & 89 & 84,8 \\
\hline & Total & 105 & 100 \\
\hline \multirow[t]{5}{*}{3} & Makanan Cepat Saj & $\overline{\text { fast } f}$ & \\
\hline & - Baik & 22 & 21,0 \\
\hline & - $\quad$ Kurang Baik & 69 & 65,7 \\
\hline & - Buruk & 14 & 13,3 \\
\hline & Total & 105 & 100 \\
\hline \multirow[t]{4}{*}{4} & Stress & & \\
\hline & - Normal & 38 & 36,2 \\
\hline & - $\quad$ Stress & 67 & 63,8 \\
\hline & Total & 105 & 100 \\
\hline \multirow[t]{5}{*}{5} & Olahraga & & \\
\hline & - $\quad$ Sering & 14 & 13,3 \\
\hline & - Rutin & 6 & 5,7 \\
\hline & - Jarang & 85 & 81,0 \\
\hline & Total & 105 & 100 \\
\hline
\end{tabular}

Sumber: data primer diolah

Dari 105 sampel yang diteliti mayoritas responden mengalami dismenorea dengan nyeri kongestif sebanyak 65 responden $(61,9 \%)$, usia menarche $<12$ tahun sebanyak 89 responden $(84,8 \%)$, mengkonsumsi makanan cepat saji (fast food) yang kurang baik sebanyak 69 responden $(65,7 \%)$, sebagian besar responden mengalami stress sebanyak 67 responden $(63,8 \%)$ dan jarang melakukan olahraga sebanyak 85 responden $(81,0 \%)$. 


\section{B. Analisis Bivariat}

Tabel 2. Hasil Tabulasi silang antara faktor Risiko dengan Dismenorea pada Remaja Putri di MAN 2 Lebak

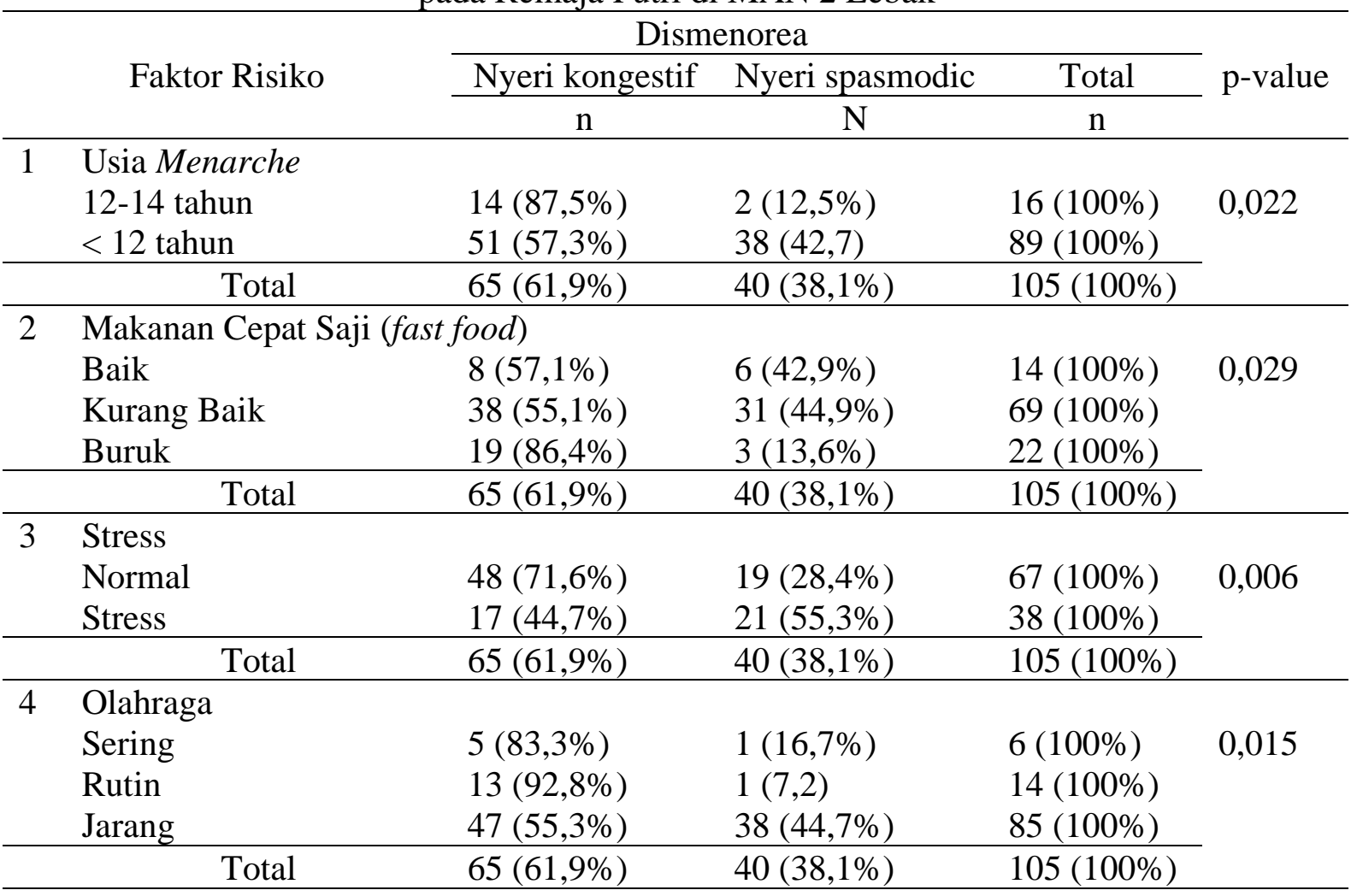

Sumber: data primer diolah

\section{Hubungan Usia Menarche dengan} Dismenorea

Berdasarkan tabel 2 hasil analisis bivariat menunjukkan adanya hubungan usia menarche dengan dismenorea dan secara statistik signifikan $\mathrm{p}<0,05(\mathrm{p}=0,022)$.

Penelitian ini sejalan dengan penelitian yang dilakukan Wardani (2021) dengan hasil 91,2 $\%$ (62 responden) yang memiliki usia menarche < 12 tahun dan menderita dismenore primer dengan $\mathrm{p}$-value $=0,000$ atau $p$ value $<\alpha(0,05)$ yang berarti terdapat hubungan antara usia menarche $<12$ tahun dengan dismenore primer. Nilai odds ratio sebesar 28,933 yang berarti bahwa siswi yang mempunyai usia menarche $<12$ tahun beresiko 28,933 kali untuk terjadi dismenore primer dibandingkan dengan siswi yang mempunyai usia menarche $>12$ tahun.

Keterkaitan usia menarche $<12$ tahun dengan dismenore terhadap wanita yang mengalami menstruasi pertama sering dibuat gelisah karena mental yang kurang siap dan perubahan hormonal. Hal tersebut salah satunya dipengaruhi usia. Menarche dapat menimbulkan berbagai masalah salah satunya yaitu keluhan nyeri saat menstruasi atau yang biasa disebut dismenore. Umumnya wanita merasakan dismenore primer. Sebanyak $90 \%$ wanita di dunia yang mengalami dismenore, lebih dari $50 \%$ diantaranya mengalami ketidaknyamanan saat menstruasi dan 10-20\% mengalami ketidaknyamanan yang parah (Wardani, 2021).

Sedangkan Menurut Widjanarko (2014), menyatakan bila menarche terjadi pada usia yang lebih awal dari normal dimana alat reproduksi belum siap untuk mengalami perubahan dan masih terjadi penyempitan pada leher rahim maka akan timbul rasa sakit ketika menstruasi. Usia menarche bervariasi, dari rentang umur 10-16 tahun. Akan tetapi usia menarche dapat di katakan normal 
apabila terjadi pada usia 12-14 tahun (Proverawati, 2009).

Peningkatan hormon prostaglandin menyebabkan kontraksi uterus yang tidak teratur dan tidak terkoordinasi. Mekanisme lain oleh prostaglandin dan hormon lain yang bisa menyebabkan nyeri adalah kemampuan beberapa hormon termasuk prostaglandin yang bisa membuat serat saraf sensori nyeri di uterus menjadi hipersensitif terhadap kerja bradikinin dan stimulus nyeri fisik maupun kimiawi lainnya (Reeder dan Koniak, 2014)

\section{Hubungan Makanan Cepat Saji (fast food) dengan dismenorea}

Berdasarkan tabel 2 hasil analisis bivariat menunjukkan adanya hubungan makanan cepat saji (fast food) dengan dismenorea dan secara statistik signifikan $\mathrm{p}<0,05$ ( $\mathrm{p}=$ $0,029)$.

Penelitian ini sejalan dengan penelitian Indahwati (2017) didapatkan bahwa dari seluruh subjek penelitian hampir setengahnya $(42.9 \%)$ atau sejumlah 27 responden sering mengonsumsi fast food dan mengalami dismenore. Berdasarkan hasil analisis frekuensi makan dan kejadian dismenore merupakan dua variabel yang saling berhubungan $(p=0.025, \alpha=0.05)$.

Supariasa (2012) menyebutkan bahwa dari kebiasaan makanan cepat saji atau fast food dapat berpengaruh pada gaya hidup dan dapat membuat gangguan ginekologi seperti dismenorea dan haid tidak teratur.

Satyanarayan (2014) menyebutkan Fast food mengandung asam lemak trans yang merupakan salah satu radikal bebas. Salah satu efek dari radikal bebas kerusakan membrane sel. Membran sel memiliki beberapa komponen, salah satunya adalah fosfolipid. Salah satu fungsi fosfolipid adalah sebagai penyedia asam arakidonat yang akan disintesis menjadi prostaglandin. Prostaglandin berfungsi membantu Rahim berkontraksi dan mengeluarkan lapisan rahim selama periode menstruasi. Jadi, pada wanita yang mengalami nyeri haid atau dismenore ada penumpukan prostaglandin dalam jumlah yang terlalu banyak sehingga menyebabkan terjadinya dismenore.

Salah satu fungsi fosfolipid adalah sebagai penyedia asam arakidonat yang akan disintesis menjadi Prostaglandin. Faktor pertama yang mempengaruhi dismenore adalah status gizi. Status gizi yang kurang selain akan mempengaruhi pertumbuhan, fungsi organ tubuh, juga akan menyebabkan terganggunya fungsi reproduksi. Hal ini akan berdampak pada gangguan haid, tetapi akan membaik bila asupan nutrisinya baik (Satyanarayana, 2014).

Makanan cepat saji merupakan makanan yang rendah zat gizi mikro namun kandungan lemak dan natrium tinggi. Ketidakseimbangan kandungan zat gizi yang terdapat pada makanan cepat saji membuat jenis makanan ini kurang baik untuk dikonsumsi setiap hari. Makanan cepat saji umumnya mengandung kalori, kadar lemak, gula dan natrium yang tinggi serta rendah kandungan serat, vitamin $\mathrm{A}$, vitamin $\mathrm{C}$, kalsium dan folat.

\section{Hubungan Stress dengan Dismenorea}

Berdasarkan tabel 2 hasil analisis bivariat menunjukkan adanya hubungan stress dengan dismenorea dan secara statistik signifikan $\mathrm{p}$ value $<0,05(\mathrm{p}=0,006)$.

Penelitian ini sejalan dengan penelitian yang dilakukan oleh Prishaningrum (2019) yang menunjukkan bahwa terdapat hubungan yang bermakna antara tingkat stress dengan dismenorea dengan hasil $\mathrm{p}$-value sebesar 0,000 .

Stres dapat mengganggu kerja sistem endokrin sehingga dapat menyebabkan menstruasi yang tidak teratur dan timbul rasa sakit saat menstruasi (Nuraini, 2021). Stress menimbulkan penekanan sensasi saraf-saraf pinggul dan otot-otot punggung bawah sehingga menimbulkan dismenorea. 
Saat seseorang mengalami stres terjadi respon neuroendokrin sehingga menyebabkan Corticotrophin Releasing Hormone (CRH) maka terjadi sekresi Adrenocorticotrophic Hormone (ACTH). ACTH akan meningkatkan sekresi kortisol adrenal. Hormon-hormon tersebut menyebabkan sekresi Follicle Stimulating Hormone (FSH) dan Luteinizing Hormone (LH) terhambat sehingga perkembangan folikel terganggu. Hal ini menyebabkan pelepasan progesteron terganggu. Kadar progesteron yang rendah meningkatkan sintesis prostaglandin. Ketidak seimbangan antara prostaglandin menyebabkan ischemia pada sel-sel miometrium dan peningkatan kontraksi uterus. Peningkatan kontraksi yang berlebihan menyebabkan dismenorea (Rohmawati, 2019).

Pengaruh stres terhadap siklus menstruasi yang tidak teratur melibatkan sistem neuroendokrinologi sebagai sistem yang besar peranannya dalam reproduksi wanita. Gangguan pada pola menstruasi ini melibatkan mekanisme regulasi integratif yang mempengaruhi proses biokimia dan seluler seluruh tubuh termasuk otak dan psikologis. Pengaruh otak dalam reaksi hormonal terjadi melalui jalur hipotalamushipofisis-ovarium yang meliputi multiefek dan mekanisme kontrol umpan balik (Tombokan, 2017).

\section{Hubungan Olahraga dengan Dismenorea}

Berdasarkan tabel 2 hasil analisis bivariat menunjukkan adanya hubungan olahraga dengan dismenorea dan secara statistik signifikan $\mathrm{p}$ value $<0,05(\mathrm{p}=0,015)$.

Penelitian ini sejalan dengan penelitian Sugiharti (2018) didapatkan hasil mahasiswa yang mempunyai kebiasaan olahraga baik sebagian besar tidak mengalami nyeri haid yaitu sebanyak 12 orang (40\%), sedangkan mahasiswa yang tidak mempunyai kebiasaan olahraga yang baik sebagian besar mengalami nyeri haid primer yaitu sebanyak
28 orang $(93,4 \%)$. Jika dilihat dari hasil analisis Chi Square menunjukkan hasil nilai $\mathrm{p}$ value adalah 0,002 yang berarti ada hubungan antara kebiasaan olahraga dengan kejadian nyeri haid primer pada remaja. Senada dengan penelitian yang dilakukan oleh Tamesvari (2019), menunjukan bahwa variabel yang behubungan dengan dismenor primer adalah kebiasaan olahraga ( $\mathrm{p}$-value $0.014)$.

Adanya hubungan kebiasaan olahraga terhadap kejadian nyeri haid primer dapat disebabkan karena olahraga merupakan salah satu teknik relaksasi yang dapat digunakan untuk mencegah timbulnya rasa nyeri. Hal ini disebabkan saat melakukan olahraga tubuh akan menghasilkan hormon endorphin. Hormon endorphin dihasilkan oleh otak dan susunan syaraf tulang belakang (Sugiharti, 2018).

Kejadian dismenorea akan meningkat pada wanita yang kurang melakukan olahraga, sehingga ketika wanita mengalami dismenorea, oksigen tidak dapat disalurkan ke pembuluh-pembuluh darah organ reproduksi yang saat itu terjadi vasokontriksi. Bila wanita teratur melakukan olahraga, maka wanita tersebut dapat menyediakan oksigen hampir 2 kali lipat permenit sehingga oksigen tersampaikan ke pembuluh darah yang mengalami vasokontriksi, Hal itu akan menyebabkan terjadinya penurunan kejadian dismenorea dengan teratur berolahraga (Tjokronegoro, 2014).

Wanita yang melakukan olahraga secara teratur setidaknya 30-60 menit setiap3-5 kali per minggu dapat mencegah terjadinya dismenorea. Setiap wanita dapat sekedar berjalan-jalan santai, jogging ringan, berenang, senam maupun bersepeda sesuai dengan kondisi masing-masing Adanya hubungan kebiasaan olahraga terhadap kejadian dismenore dapat disebabkan karena olahraga merupakan salah satu teknik relaksasi yang dapat digunakan untuk mengurangi nyeri (Manuaba, 2012). 
Kebiasaan olahraga merupakan kegiatan fisik olah raga yang dilakukan responden meliputi senam,lari/joging, bersepeda, renang, jalan sehat. Olahraga secara teratur diyakini bermanfaat untuk mengurangi hiperplasia endometrium dan menurunkan produksi prostaglandin. Melakukan latihan fisik menyebabkan reseptor di dalam hipotalamus dan sistem limbik yang berfungsi untuk mengatur emosi menangkap hormon $\beta$-endorphin yang dapat dihasilkan setelah seseorang melakukan aktivitas fisik. Peningkatan $\beta$-endorphin telah terbukti berhubungan erat dengan penurunan rasa nyeri, peningkatan daya ingat, memperbaiki nafsu makan, kemampuan seksual, tekanan darah dan pernapasan (Temesvari, 2019).

\section{KESIMPULAN}

Kesimpulan dalam penelitian ini ada hubungan statistik signifikan antara usia menarche, makanan cepat saji (fast food), stress dan olahraga dengan kejadian dismenorea.

\section{SARAN}

Saran untuk penelitian selanjutnya bisa meneliti dengan faktor lain misalnya siklus menstruasi, status gizi, kadar $\mathrm{Hb}$ dan perokok pasif.

\section{DAFTAR PUSTAKA}

Agustini, R. 2019. Hubungan Usia Menarche dengan kejadian Dismenore pada Siswi Kelas VIII SMP N 3 Gamping Ygyakarta. Skripsi. Universitas Aisyiyah Yogyakarta.

Indahwati, A.N., Elmie, M., \& Dian, L.P. Hubungan

Mengkonsumsi

Makanan Cepat Saji (Fast food) Dengan Kejadian Dismenore Pada Remaja Putri Di SMP N 1 Ponorogo. Indonesian Journal of Health Sciences Sci., vol.1, no.2, pp. 7-13, 2017

Gumangsari, N.M. (2014). Pengaruh Massage Counterpressure Terhadap
Penurunan Tingkat Nyeri Haid Pada Remaja Putri Di SMA N 2 Ungaran Kabupaten Semarang Tahun 2014. Jurnal Kesehatan Stikes Ngudi Wariyono Ungaran 1-12.

Manuaba. 2012, Kapita Selekta Pelaksanaan Rutin Obsterti Ginekologi dan KB. Penerbit Buku Kedokteran EGC : Jakarta

Nuraini, S., Yasmin, S.S., \& Evi, F. Hubungan Usia Menarche, Status Gizi, Stres, dan Kadar Hemoglobin Terhadap Kejadian Dismenorea Primer pada Mahasiswi Fakultas Kedokteran, Universitas Mulawarman. J.Sains Kes. 2021. Vol 3. No 3. pISSN:2303-0267, e-ISSN:24076082

Pintam, dkk. (2018). Aktivitas fisik remaja dalam mengatasi dismenore. Jurnal kesehatan Ibu dan Anak Akademi Kebidanan An-nur 2018. PDF.

Prishaningrum, A.A.R. (2019) Hubungan Tingkat Stres Terhadap Tingkat Dismenore Pada Remaja Usia 16-18 Tahun Di Pondok Pesantren An-Nur Komplek Al-Maghfirah Ngrukem Sewon Kabupaten Bantul. Skripsi, Poltekkes Kemenkes Yogyakarta.

Proverawati. (2009). Menarche menstruasi pertama penuh makna. Yogyakarta : penerbit mulia-medika

Rohmawati, W., \& Wulandari, D. A. (2019). Faktor yang Berhubungan dengan Nyeri Dismenore Primer pada Siswi di SMA Negeri 15 Semarang . Jurnal Bidan Cerdas Volume 2 No.2 , 84-91.

Satyanarayan. Kebiasaan Makanan Cepat Saji (fast food) modern, Aktivitas fisik dan Faktor lainnya denganStatus Gizi Pada Mahasiswa Penghuni Asrama UI Depok Tahun 2014," UI Depok, Depok, 2014

Sugiharti, R.K., \& Tri, S. Hubungan Antara Kebiasaan Olahraga dengan Kejadian Nyeri Haid Primer Pada Remaja. Bidan Prada: Jurnal 
Publikasi Kebidanan, Vol. 9 No. 1

Edisi Juni 2018, hlm 114-123

Sugiyono. 2018. Metode Penelitian Kuantitatif, Kualitatif dan R\&D.

Bandung: Penerbit Alfabeta.

Temesvari, N.A., Loli, A., \& Witri, Z.Q. Efek Olahraga terhadap Kejadian Dismenor Primer pada Siswi Kelas X SMA Negeri 78 Jakarta Barat. JURNAL MKMI, Vol. 15 No. 3, September 2019

Tjokronegoro, Arjatmo, 2014. Olahraga dan kebugaran jasmani. Jakarta : balai penerbitan FKUI.

Tombokan, K.C., Damajanty, H.C.P., \& Joice, N.A.E. Hubungan antara stres dan pola siklus menstruasi pada mahasiswa Kepaniteraan Klinik Madya (co-assistant) di RSUP Prof. Dr. R. D. Kandou Manado. Jurnal eBiomedik (eBm), Volume 5, Nomor 1, Januari-Juni 2017

Widjanarko, B. Tinjauan Terapi pada Dismenore Primer. Majalah Kedokteran Damianus. Vol 5 (16) November 2006: 2014

Wardani, P.K., Fitriani., \& Saras, C.C. Hubungan Siklus Menstruasi dan Usia Menarche dengan Dismenor Primer pada Siswi Kelas X. Jurnal Ilmu Kesehatan Indonesia (JIKSI) E-ISSN: 2745-8555 Vol. 2, No. 1, Februari 2021 